\title{
MENDORONG KREATIVITAS DAN KETERAMPILAN DALAM MENEMUKAN PELUANG USAHA PADA IBU RUMAH TANGGA DUSUN KULUBANYU, KABUPATEN MOJOKERTO
}

\author{
Limpad Luhung Anggakara \\ Program Studi Akuntansi, Fakultas Ekonomi, Universitas Negeri Surabaya \\ e-mail: anggakara111@gmail.com
}

\begin{abstract}
Abstrak
Kegiatan ekonomi mikro kecil dan menengah merupakan roda penggerak roda perekonomian daerah itu sendiri sehingga keberadaan pelaku Usaha Mikro Kecil Menengah (UMKM) perlu mendapatkan perhatian dari pemerintah, khususnya pemerintah daerah itu sendiri. Dalam menjalankan sebuah usaha tentunya akan mengalami berbagai kendala baik dari internal maupun eksternal usaha, adapun kendala internal yang mungkin saja terjadi antarai lain : kualitas SDM yang belum mencukupi, akses dan pengembangan pangsapasar yang lemah, modal yang terbatas, penguasaan teknologi yang terbatas, dan manajemen yang buruk Selain itu terdapat ancaman dari luar usaha yang dapat mengancam keberlangsungan suatu usaha, salah satunya adalah persaingan bisnis Adanya persaingan ini juga memberi peluang bagi pemilik usaha yang responsif terhadap perubahan lingkungan. Sebagai upaya mendorong kreativitas dan keterampilan mayarakat Dusun Kulubanyu diadakan kegiatan bina desa yang yang diselenggarakan selama 6 bulan dengan sasaran dari bina desa tersebut adalah ibu-ibu Dusun Kulubanyu. Adapun metode pelaksanaan dari bina desa ini antara lain : sosialisasi tentang home industry, pelatihan pembuatan "Dangkrik (Gedhang Kripik)", memberikan edukasi terkait dengan pemasaran produk melalui media sosial. Hasil menunjukkan bahwa adanya peran aktif ibu-ibu masyarakat Dusun Kulubanyu dalam mengikuti rangakaian kegiatan bina desa hingga terciptanya produk unggulan hasil dari kreativitas dan inovasi masyarakat Dusun Kulubanyu.
\end{abstract}

Kata Kunci: Inovasi Produk, Kewirausahaan, Kripik Pisang

\begin{abstract}
Micro, small and medium economic activities is the driving wheels of the regional economy itself so that the existence of micro, small and medium enterprises (MSMEs) needs to get attention from the government, especially the regional government itself. In running a business, of course, you will experience various obstacles both from internal and external to the business, as for internal constraints that may occur, there are: inadequate quality of human resources, weak access and development of market share, limited capital, limited mastery of technology, and bad management. Moreover, there are threats from outside the business that can threaten the sustainability of a business, one of them is business competition. This competition also provides opportunities for business owners who are responsive to environmental changes. In an effort to encourage creativity and skills of the people of Kulubanyu Hamlet, village development activities were held for 6 months with the target of the village development being the women of Kulubanyu Hamlet. The implementation methods of this village development include: socialization about the home industry, training on making "Dangkrik (Gedhang Kripik)", providing education related to product marketing through social media. The results show that there is an active role of the women of the Kulubanyu community in following a series of village development activities to create superior products resulting from the creativity and innovation of the people of Kulubanyu Hamlet.
\end{abstract}

Keywords: Product Innovation, Entrepreneurship, Banana Chips

\section{PENDAHULUAN}

Perekonomian daerah merupakan salah satu faktor penentu pertumbuhan ekonomi suatu Negara. Kegiatan ekonomi mikro kecil dan menengah merupakan roda penggerak roda perekonomian daerah itu sendiri sehingga keberadaan pelaku Usaha Mikro Kecil Menengah (UMKM) perlu mendapatkan perhatian dari pemerintah, khususnya pemerintah daerah itu sendiri (Darwis et al., 2020). UMKM sering dihubungkan dengan kondisi terkini dari sosial masyarakat yang saat ini sedang dialami oleh Indonesia, seperti kemiskinan, tingkat pengangguran yang tinggi, kesenjangan ekonomi, dan dampak negarif lainnya seperti urbanisasi dan defisit neraca pembayaran. Berdasarkan data yang diperoleh dari Badan pusat statistik, pada tahun 2018 
Indonesia telah memiliki 62 juta unit UMKM, mayoritas dimulai dan dibentuk oleh seorang wirausaha (Sepris, 2018).

Kewirausahaan merupakan sebuah proses yang bertujuan untuk menciptakan nilai tambah atas barang ataupun jasa yang dihasilkan (Armalinda, 2020). Antonites \& Van Vuuren (2014) mendefinisikan wirausaha sebagai seseorang yang memiliki pandangan dan pemikiran ke depan dalam melihat peluang usaha. Inti dari kewirausahaan adalah menciptakan sesuatu yang baru berupa sebuah produk ataupun jasa melalui pemikiran kreatif dan tindakan inovatif.

Dalam menjalankan usahanya, seorang wirausaha tentunya akan mengalami berbagai kendala baik dari internal maupun eksternal usaha, adapun kendala internal yang mungkin saja terjadi antarai lain : kualitas SDM yang belum mencukupi, akses dan pengembangan pangsapasar yang lemah, modal yang terbatas, penguasaan teknologi yang terbatas, dan manajemen yang buruk, (Darwis et al., 2020). Selain itu terdapat ancaman dari luar usaha yang dapat mengancam keberlangsungan suatu usaha, salah satunya adalah persaingan bisnis. Adanya persaingan ini juga memberi peluang bagi pemilik usaha yang responsif terhadap perubahan lingkungan. Pelaku usaha harus bersaing dalam menciptakan minat beli dalam diri konsumen mereka. Salah satu faktor yang diduga memiliki pengaruh besar terhadap minat beli konsumen adalah inovasi produk. Karena sebelum melakukan pembelian produk, konsumen akan membandingkan produk yang akan dibeli dengan produk yang ditawarkan oleh usaha lain. Oleh sebab itu inovasi produk atau jasa harus dilakukan guna menarik minat beli konsumen (Maulana \& Alisha, 2020).

Pemikiran yang telah diutarakan oleh Darwis et al., (2020) dan Maulana \& Alisha, (2020) relevan dengan kondisi Dusun Kulubanyu, Kabupaten Mojokerto yang kaya akan potensi hasil perkebunan karena lokasi dusun yang berada di wilayah pegunungan, namun hasil hasil bumi yang diperoleh langsung dijual tanpa diolah terlebih dahulu sehingga nilai jual hasil bumi yang kecil dan minat beli konsumen yang rendah karena tidak adanya inovasi hasil bumi yang ditawarkan oleh masyarakat Dusun Kulubanyu. Masyarakat Dusun Kulubanyu masih beranggapan bahwa kesuksesan hanya bisa diperoleh dari kerja kantoran dan bekerja pada perusahaan yang besar. Hal ini dikarenakan kurangnya pengetahuan dan kreativitas warga Dusun Kulubanyu dalam memanfaatkan peluang bisnis. Dari permasalahan tersebut penulis melakukan kegaiatan pengabdian masyarakat sebagai sarana pemberian solusi dalam rangka optimalisasi dan pengembangan sumberdaya alam dan manusia yang ada di Dusun Kulubanyu. Khususnya dalam pengelolaan pisang, sehingga dapat menciptakan suatu produk yang dapat menjadi produk unggulan desa serta menambah nilai jual dalam pisang tersebut, dimana pisang tersebut akan diolah menjadi "Dangkrik" (Gedang Kripik) beranekaragam rasa yang bergizi dan bernilai jual tinggi. Hal ini dilakukan dengan tujuan untuk mendorong kreativitas dan keterampilan dalam menemukan peluang usaha bagi warga Dusun Kulubanyu.

\section{METODE}

Melihat kondisi masyarakat Dusun Kulubanyu yang masih beranggapan bahwa kesuksesan hanya bisa diperoleh dari kerja kantoran dan bekerja pada perusahaan yang besar, maka metode pelaksanaan yang dipilih nantinya adalah bina desa yang akan dilaksanakan secara berkala selama 6 bulan mulai dari 1 Juni 2019 sampai dengan 19 November 2019, agar masyarakat memiliki sebuah kebiasaan baru yang bermanfaat, dan diharapakan dapat menaikkan penghasilan masyarakat Dusun Kulubanyu melalui sebuah produk yang dapat menarik konsumen. Adapun rincian kegiatan bina tersebut antara lain : menjalin kerja sama dengan perangkat Dusun Kulubanyu, memberikan sosialisasi tentang home industry, pelatihan pembuatan "Dangkrik (Gedhang Kripik)", memberikan edukasi terkait dengan pemasaran produk melalui media sosial, Sasaran kegiatan bina desa ini adalah ibu-ibu dan msyarakat yang berada di Dusun Kulubanyu.

\section{HASIL DAN PEMBAHASAN}

Kegiatan bina desa ini dilakukan di Dusun Kulubanyu, Desa tawangrejo, Kabupaten Mojokerto. Lokasi ini dipikih karena daerah ini memiliki hasil bumi yang melimpah dan dari hasil survei Jurusan Akuntansi Uyang telah dilakukan tim bina desa mendapatkan respon yang baik dari masyarakat. Sebelum melakukan kegiatan bina desa, tim bina desa menemui perangkat desa terlebih dahulu untuk meminta izin melakukan kegiatan bina desa selama 6 bulan dan menjelaskan kegiatan yang nantinya akan dilakukan di Dusun Kulubanyu, selain itu tim juga menanyakan 
terkait aktivitas warga Dusun Kulubanyu setiap harinya serta berdiskusi dengan masyarakat yang dirasa dapat menjadi penggerak warga lainnya. Waktu yang diperlukan untuk menyelesaikan tahapan ini sampai dengan proses administrasi selesai adalah 1 bulan.

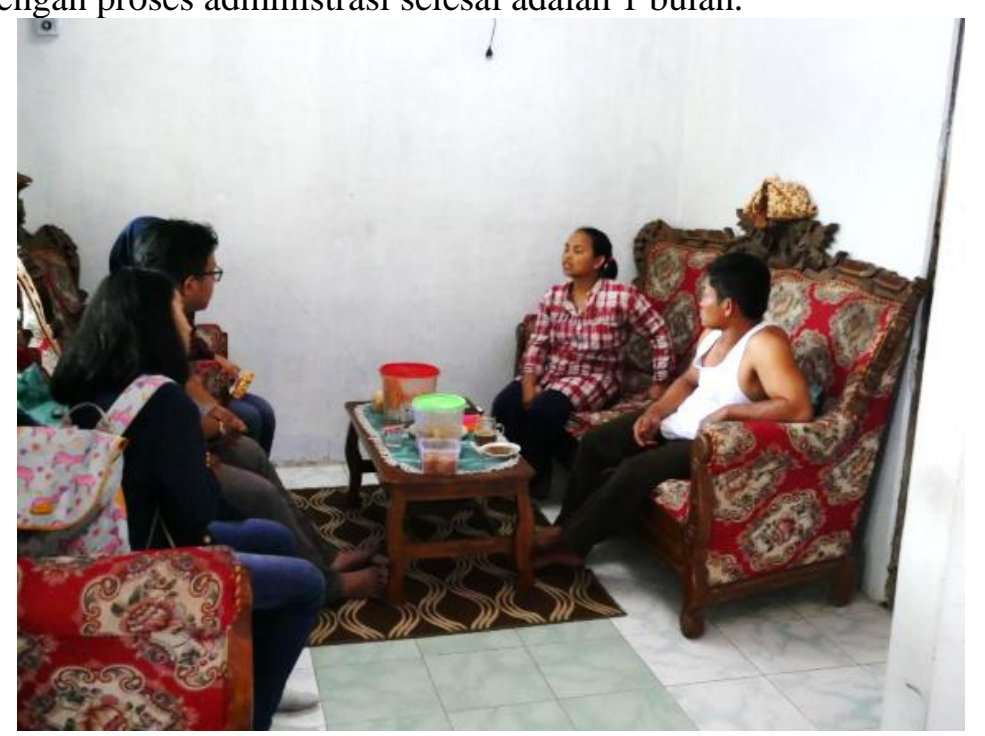

Gambar 1. Proses Diskusi dengan Perangkat Desa

Kegiatan yang akan dilakukan selanjutnya adalah mengundang maskarayat Dusun Kulubanyu khususnya ibu-ibu rumah tangga untuk menghadiri kegiatan penyuluhan terkait Home Indusry yang disampaikan oleh Dosen Kewirausahaan Jurusan Akuntansi Unesa, tujuan diadakannya penyuluhan ini adalah membuka pola pikir baru masyarakat tentang pentingnya pemikiran yang maju untuk mencapai kesuksesan dimasa yang akan daaing serta membahas hasil bumi yang nantinya akan diolah hingga munculah sebuah ide produk yaitu "Dangkrik (Gedhang Kripik)" yang dimana kripik pisang tersbut akan diberi dengan perasa yang sedang disukai oleh masyarakat saat ini, varian rasa "Dangkrik" yang akan diproduksi antara lain : coklat, taro, matcha, balado, dan keju. Selain itu, dalam penyuluhan ini juga membahas media promosi yang sekiranya dapat digunakan dengan mudah oleh warga dusun kulubanyu yaitu melalui media sosial khususnya instagram instagram. Instagram dipilih karena mudah digunakan dan memiliki pengguna aktif yang banyak serta pengguna dari instagram mencakup seluruh golongan masyarakat. Setelah pelaksanaan penyuluhan Home Industry selesai tim bina desa melakukan diskusi dengan peserta penyuluhan Home Industry yang berjumlah 25 orang. Hasil dari diskusi tersebut adalah prosedur produksi "Dangkrik" dan terbentuknya 4 kelompok produksi yang nantinya akan memproses pembuatan "Dangkrik" berdasarkan varian rasa. Kelompok usaha ini dibentuk guna proses produksi semakin tertata.

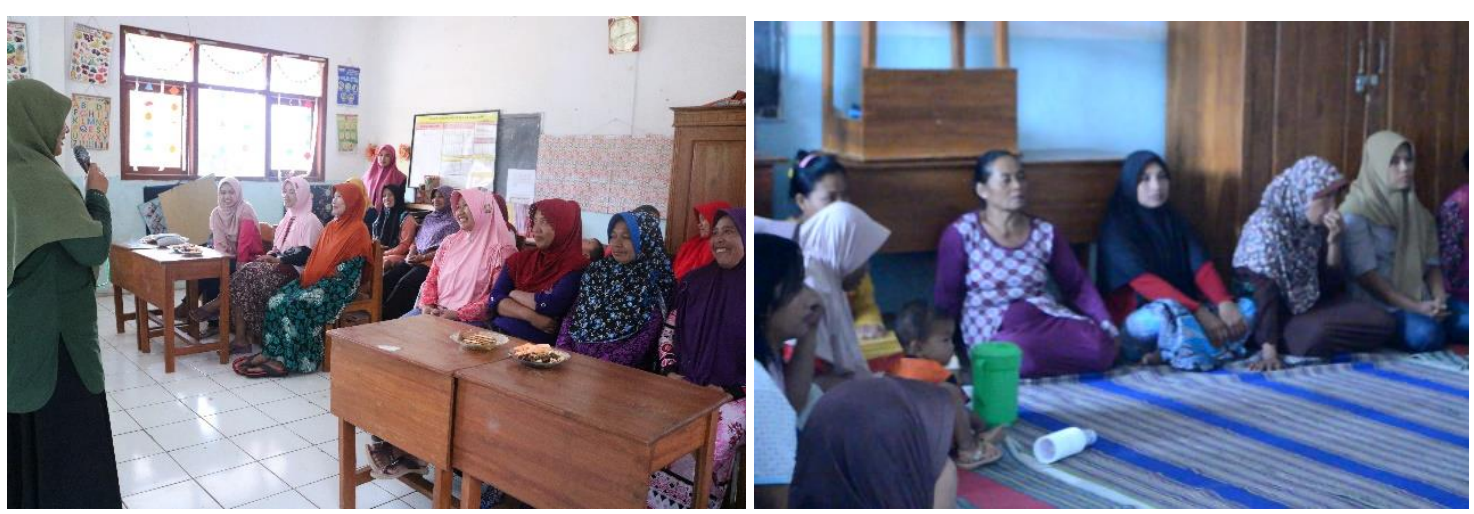

Gambar 2. Kegiatan Penyuluhan Home Industry \& Diskusi Kelompok Usaha

Rumah produksi merupakan sebuah keharusan yang dimiliki dalam melakukan produksi "Dangkrik". Tujuan dari adanya rumah produksi antara lain memudahkan kelompok usaha dalam 
memproduksi "Dangkrik", yang dimana tempat tersebut dikondisikan dengan keadaan yang bersih, steril, dan nyaman sehingga kualitas dari "Dangkrik" terjamin dan anggota kelompok usaha dapat melakukan kegiatan produksi "Dangkrik" dengan lancar. Selin itu, dengan adanya rumah produksi ini akan mempermudah untuk memperoleh PIRT, karena rumah produksi yang bersih, dan steril merupakan salah satu syarat penting dalam syarat pengajuan PIRT.

Kegiatan produksi dari "Dangkrik" ini dilaksanakan 3 kali dalam 6 bulan kegiatan bina desa yaitu pada tanggal 16, 23 Juli dan 1 September 2019. Penentuan tanggal produksi disesuaikan dengan kesediaan bahan baku. Dalam sekali proses produksi "dangkrik" menghasilkan kurang lebih 300 kemasan "Dangkrik" yang siap dijual. Adapun bahan yang diperlukan dalam sekali proses produksi "Dangkrik" antara lain :

Tabel 1. Bahan baku "Dangkrik"

\begin{tabular}{cllll}
\hline No & \multicolumn{1}{c}{ Nama } & \multicolumn{1}{c}{ Kuantitas } & \multicolumn{1}{c}{ Harga Satuan } & \multicolumn{1}{c}{ Jumlah } \\
\hline 1. & Pisang & 2 tundun & Rp. 100,000,- & Rp. 200.000,- \\
2. & Minyak goreng & & & Rp. 94.000,- \\
3. & Pewarna makanan & 4 botol & Rp. 2,000,- & Rp. 8,000,-- \\
4. & Label & 28 lembar A3 & Rp. 2,500,- & Rp. 70,000,- \\
5. & Kemasan & 3 Pack & Rp. 90,000,- & Rp. 270,000,- \\
6. & Coklat Bubuk & 150 gram & & Rp. 21,000,- \\
7. & Kayu bakar & 2 & & Rp. 30,000,- \\
8. & Keju & 150 gram & & Rp. 19,000,- \\
9. & Balado & 300 gram & & Rp. 15,000,- \\
10. & Melted Greentea & 3 & Rp. 8,500,- & Rp. 25,500,- \\
11. & Melted Coklar & 3 & Rp. 8,000,- & Rp. 24,000,- \\
12. & Gula Halus & 1 Kilogram & & Rp. 16,000,- \\
13. & Transportasi & & & Rp. 150,000,- \\
\hline \hline
\end{tabular}
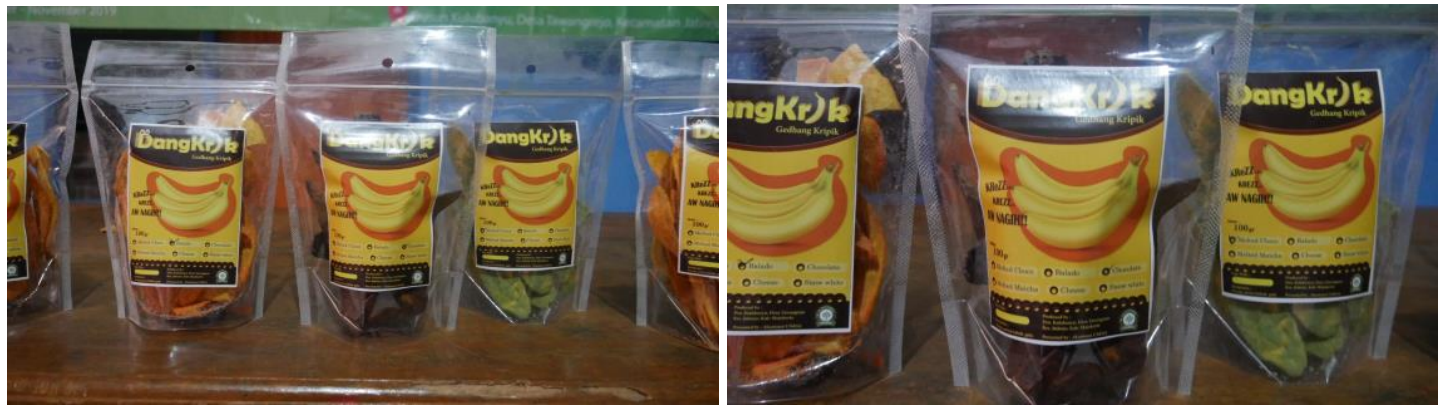

Gambar 3. Foto produk "Dangkrik"

\section{SIMPULAN}

Kegiatan bina desa dalam mendorong kretivitas dan keterampilan dalam menemukan peluang usaha pada ibu rumah tangga Dusun Kulubanyu, Kabupaten Mojokerto. Menghasilkan hasil yang baik yaitu kelompok usaha memiliki kreativitas dan inovasi dalam mengolah "Dangkrik" hal itu dibuktikan dalam sesi diskusi pembentukan kelompok usaha yang dimana terdapat anggota kelompok usaha yang ikut serta dalam menyusun prosedur pembuatan "dangkrik" untuk memperoleh kualitas yang baik hingga terciptanya produk unggulan dari Dusun Kulubanyu. Selain itu, penyuluhan Home Industry membuat warga menjadi lebih sadar dalam pentingnya menjaga dan terbentuknua kemandirian warga Dusun Kulubanyu dalam berwirausaha khusunya dalam pengelolaan "Dangkrik".

\section{SARAN}

Kegiatan bina desa ini dilakukan kurang lebih selama 6 bulan namun dalam pelaksanaan produksi "Dangkrik" hanya dapat dilaksanakan 3 kali dan waktu untuk memasarkan produk yang 
singkat, selain itu dalam hal pemasaran, "Dangkrik" masih belum dikenal oleh masyarakat yang tinggal disekitaran Dusun Kulubanyu. Untuk program bina desa kedepannya diharapkan dapat memaksimalkan waktu yang tersedia untuk melakukan produksi dan penjualan dari "Dangkrik" serta mengenalkan "Dangkrik" di kecamatan-kecamatan yang ada di Kabupaten Mojokerto.

\section{UCAPAN TERIMA KASIH}

Tim bina desa mengucapkan teima kasih kepada bapak Kepala Desa Tawangrejo, Sekretaris Desa, dan kepala Dusun Kulubanyu serta kelompok produksi yang merupakan masyarakat Dusun Kulubanyu itu sendiri yang telah memberikan kesempatan, usaha, waktu, tempat selama melaksanakan kegiatan bina desa selema kurang lebih 3 bulan hingga dapat terlaksana dengan baik. Tidak lupa ucapan termia kasih kepada seluruh tim bina desa Universitas Negeri Surabaya yang telah mengupayakan sebaik mungkin agar program bina desa dapat terlaksana di Dusun Kulubanyu ini.

\section{DAFTAR PUSTAKA}

Antonites, A., \& Van Vuuren, J. (2014). Inducing entrepreneurial creativity, innovation and opportunity-finding skills. South African Journal of Economic and Management Sciences, 8(3), 255-271. https://doi.org/10.4102/sajems.v8i3.1197

Armalinda. (2020). PENYULUHAN DALAM MENUMBUHKAN JIWA WIRAUSAHA DAN MEMULAI USAHA PRODUKTIF PADA MASYARAKAT DESA BANDUNG AGUNG KECAMATAN PAGAR GUNUNG KABUPATEN LAHAT. Suluh Abdi: Jurnal Ilmiah Pengabdian Kepada Masyarakat, 2(1), 27-30.

Darwis, R. S., Sulastri, S., \& Irfan, M. (2020). Pengembangan Potensi Wirausaha Di Desa Mekargalih, Kecamatan Jatinangor Kabupaten Sumedang. 3, 116-126.

Maulana, Y. S., \& Alisha, A. (2020). Inovasi Produk dan Pengaruhnya Terhadap Minat Beli Konsumen (Studi Kasus pada Restoran Ichi Bento Cabang Kota Banjar). Inovbiz: Jurnal Inovasi Bisnis, 8(1), 86. https://doi.org/10.35314/inovbiz.v8i1.1313

Sepris, Y. (2018). KEWIRAUSAHAAN BAGI INDUSTRI KECIL MENENGAH DI KOTA PADANG DALAM RANGKA PENINGKATAN KEMAMPUAN MANAJEMEN DAN PERLUASAN PASAR. Jurnal Pengabdian Kepada Masyarakat Dewantara, 1. https://doi.org/https://doi.org/10.31317/jpmd.v1i1\%20Septembe.319 